\title{
Maximum Power Point Tracker Based Digital One Cycle Control Applied in PV Systems
}

\author{
A. C. Q. B. Leite, A. O. Salazar and J. T. Carvalho \\ LAMP - PETROLEUM MEASUREMENT ASSESSMENT LABORATORY \\ UFRN, Universidade Federal do Rio Grande do Norte \\ Central Campus - Natal (Brasil) \\ E-mail: alan.queiroz.leite@gmail.com, andres@dca.ufrn.br, joaoteixeira@dca.ufrn.br
}

\begin{abstract}
The Photovoltaic energy shown an alternative to meet the growing energy demand and reduce dependence on fossil fuels. This paper makes an approach to the need to extract the maximum power of photovoltaic panels via algorithms, such as the constant voltage. It was also used a tracking algorithm based on temperature measurement, where it returns the value of the reference voltage when a temperature change occurs. To make the switching controller was used the one cycle control OCC by presenting a higher speed of convergence, disturbance rejection of the source and no steady-state error. It was implemented in a DC-DC Boost converter to extract the maximum power of the panel and was observed that OCC is faster than PWM and the temperature algorithm was more efficient than a pure constant voltage method.
\end{abstract}

\section{Key words}

MPPT, OCC, PV Systems, Arduino.

\section{Introduction}

The use of photovoltaic systems has grown significantly in recent years to meet the growing demand, particularly in countries like Germany and Spain. These systems are becoming increasingly common in the homes of the population, so they need to be reliable, fast and secure. The PV Systems have an advantage over other renewable energy resources, as they directly convert light energy from the sun into electricity. This makes them a suitable choice in many applications.

The PV Systems are made up of three stages: a photovoltaic panel that converts light radiation into electrical energy for the system, a tracking algorithm that reads panel variables such as voltage, temperature and light radiation and defines the most suitable operating point and power stage operating in the system causing the PV panel to operate the calculated operating point.

The PV panel manufacturers provide some important information in their catalogues as the maximum power voltage $\mathrm{V}_{\mathrm{MPP}}$, maximum power current $\mathrm{I}_{\mathrm{MPP}}$, open circuit voltage $\mathrm{V}_{\mathrm{OC}}$ and short-circuit current $\mathrm{I}_{\mathrm{SC}}$ of panel. The interpretation of this information is very important to design of PV Systems. The photovoltaic panels are sensitive to radiation variation which may cause a drop in generate power, so one should avoid the shading therein. This is because the amount of photons per second decrease, thus the current photogenerated decreases. Another factor that greatly influences the power generated by the panes is the temperature of the photovoltaic cells. The high temperatures cause a loss in power generated due to the increase of energy between electrons, causing the voltage to decrease. These effects may be seen in Fig. 1.

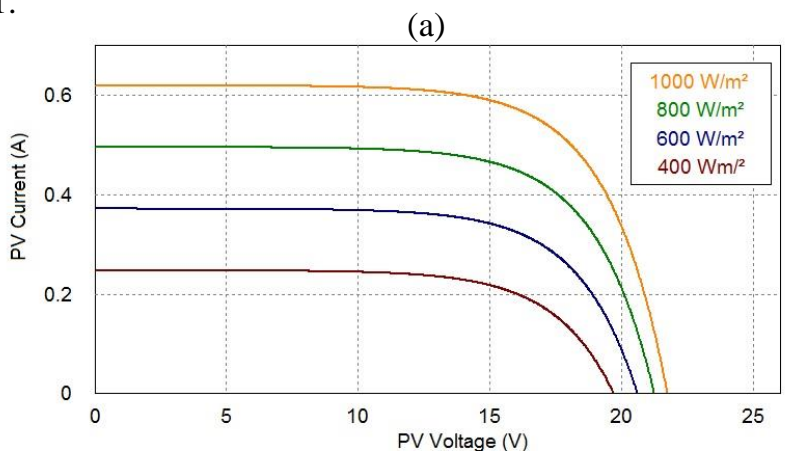

(b)

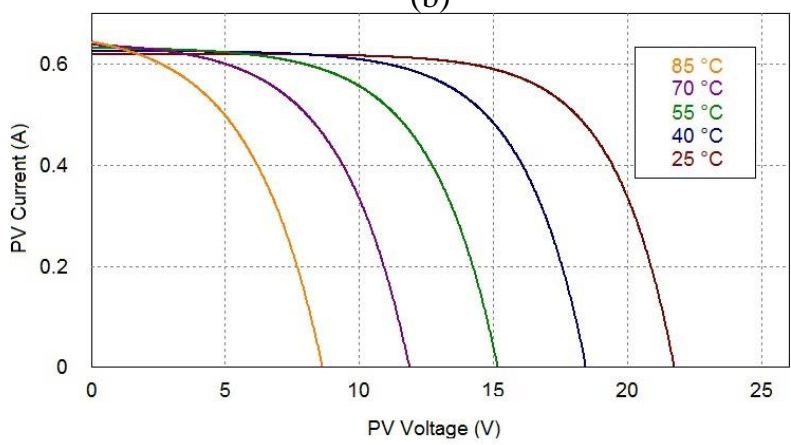

Fig. 1. I-V curves (a) under constant temperature and varying the radiation. (b) at a constant radiation varying the temperature.

In photovoltaic systems, a tracking algorithm is necessary to force the panel to work on a specific point, usually at the point of maximum power being generated, i.e. it works in MPP point (Maximum Power Point). This algorithm is done through a scheme MPPT (Maximum Power Point 
Tracker) which is a system to maximize the panel power flow to the load. The main problem to track the maximum power point is that it depends on two factors that vary widely, which are the light radiation and panel temperature, which has already seen its effects. To try to overcome this problem are proposed several methods that can be differentiated into various features, including the types of sensors required, the convergence speed, cost, scale efficiency and the application requirements for hardware.

Due to non-linearities of photovoltaic panels and switched converters, robustness, dynamic response and disturbance rejection should be considered in the MPP tracking mechanism. The conventional modulation control is slow to respond to the disturbance of the photovoltaic panel and a large number of switching cycles may be required before steady state is reached again. The modulation methods commonly used for converters are pulse-width modulation (PWM). In recent studies in the literature that implement non-linear controllers, in order to correct voltage problems in the converter output in relation to disturbances in photovoltaic systems.

The controller that will work is the OCC modulator (OneCycle Control) which has a low cost of implementation and provides a rapid response in one clock cycle without undesirable transient. Some studies compared the OCC technique with control techniques based on PWM. [1], [2] shown that this technique is capable of rejecting perturbation of power source, following the control reference in one cycle and null steady-state error.

In this work, we mitigate the characteristic of a PV system operating with an OCC control scheme, check the behaviour of power being delivered by the panel varying some parameters such as light radiation and panel temperature. The OCC modulation characteristics together with MPP tracking algorithm in a DC-DC Boost converter providing a quick response, a good tracking references, disturbance rejection and good dynamic response. The model of the photovoltaic system and the MPPT algorithm proposed in this work are shown in Section 2. The idea of Maximum Power Point Tracking algorithm is shown in Section 3. Section 4 introduces the OCC control theory. Section 5 is devoted to a discussion of the simulation results and the conclusions in the Section 6.

\section{Model System}

The photovoltaic system addressed in this study, shown in Fig. 2, is divided into three parts: the photovoltaic panel responsible for generating electrical power, a Boost converter that sets a power stage to provide power to the load and a tracking algorithm that reads panel variables and calculates the MPP point. The panel of system proposed is the commercial model KS10 from Kyocera and has the following characteristics in STC conditions (Standard Test Conditions) or $1000 \mathrm{~W} / \mathrm{m}^{2}$ radiation, $25^{\circ} \mathrm{C}$ and 1,5 air mass index (AM): open circuit voltage $\mathrm{V}_{\mathrm{OC}}=$ $21,5 \mathrm{~V}$, short-circuit current $\mathrm{I}_{\mathrm{CC}}=0,62 \mathrm{~A}$, maximum power voltage $\mathrm{V}_{\max }=16,95 \mathrm{~V}$, a maximum current $\mathrm{I}_{\max }=$ $0,55 \mathrm{~A}$ and a maximum power $\mathrm{P}_{\max }=10 \mathrm{~W}$. In [3], the circuit was implemented using analogue controllers, since this work was used by digital controllers offer greater flexibility of implementation, not suffer from the saturation of amplifiers and parameterization more precise controller.

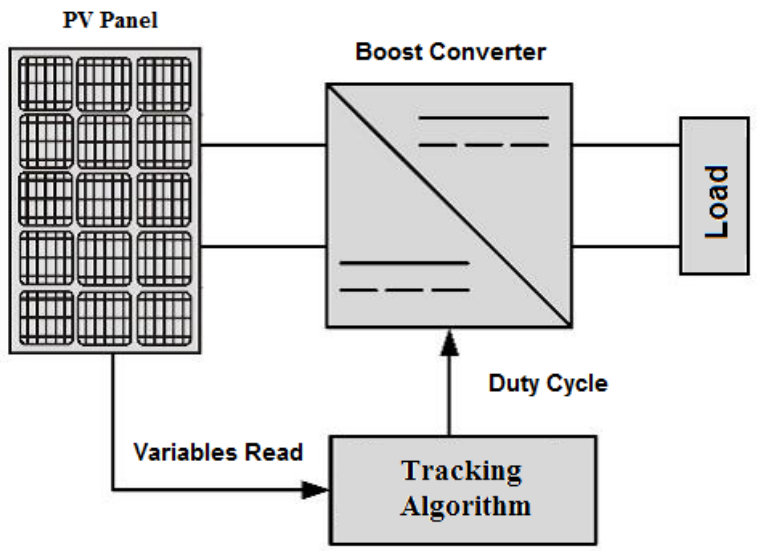

Fig. 2. Photovoltaic system diagram.

\section{Algorithm Maximum Power Point Tracking}

As the characteristic of the panel curve is not linear, the photovoltaic panels must be connected to a converter, causing the panel to operate at a particular duty cycle, D. The goal of the MPPT algorithm is to determine the optimum duty cycle for the purpose of the panel to provide MPP load.

Boost DC-DC converter is used to raise the PV module voltage to the load being a good candidate for interfacing between photovoltaic panels and the system output load. In Fig. 3, $\mathrm{V}_{\mathrm{g}}(\mathrm{t})$ is the output voltage of the photovoltaic panel, $\mathrm{L}$ is the inductor, $\mathrm{S}$ is the switching element (MOSFET), $\mathrm{R}_{\mathrm{L}}$ is the inductor resistance, $\mathrm{i}_{\mathrm{L}}(\mathrm{t})$ is the current in the inductor, $\mathrm{C}$ is the capacitor, $\mathrm{R}$ is the system output load and $\mathrm{V}_{\mathrm{o}}(\mathrm{t})$ is the system output voltage. The converter used in this study operates in continuous conduction mode.

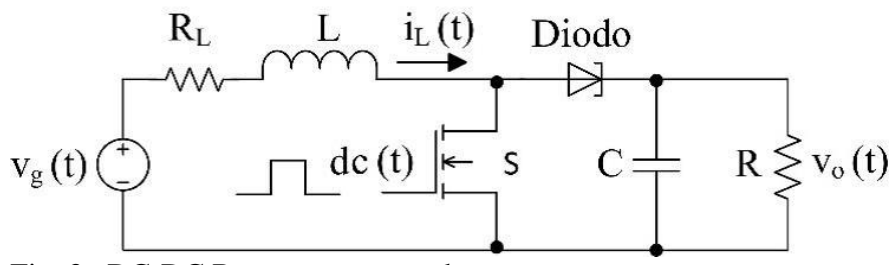

Fig. 3. DC-DC Boost converter scheme.

The method of constant voltage, $\mathrm{CV}$, is one of the simplest methods, since it consists in maintaining $\mathrm{V}_{\mathrm{pv}}$ module voltage to a reference value $\mathrm{V}_{\mathrm{pv}(\mathrm{ref})}$ which, according to the graphical $\mathrm{P}-\mathrm{V}$ corresponds to the maximum power point. This $\mathrm{V}_{\mathrm{pv}(\mathrm{ref})}$ is around $70 \%-80 \%$ of the $\mathrm{V}_{\mathrm{OC}}$ voltage [4]. Therefore, a positive point is that only PV voltage is necessary to be measured. This method operates in the DC-DC converter, updating the duty cycle and imposing the reference voltage as operating point. In Figure 4 (a) we note that for a constant temperature, the maximum power point moves nearly horizontally, i.e. for any radiation level voltage that ensures maximum 
throughput and power is practically the same, it's enclosed within a small range $\Delta \mathrm{V}_{\mathrm{mpp}}$. However, when there is variation in the cell temperature, the MPP voltage is considerably changed, not coinciding most with the reference value, being clipped, causes the module to operate outside the maximum power point. This situation is shown in Figure 4(b) causing the voltage having a $\Delta \mathrm{V}_{\mathrm{mp}}$ deviation.

(a)

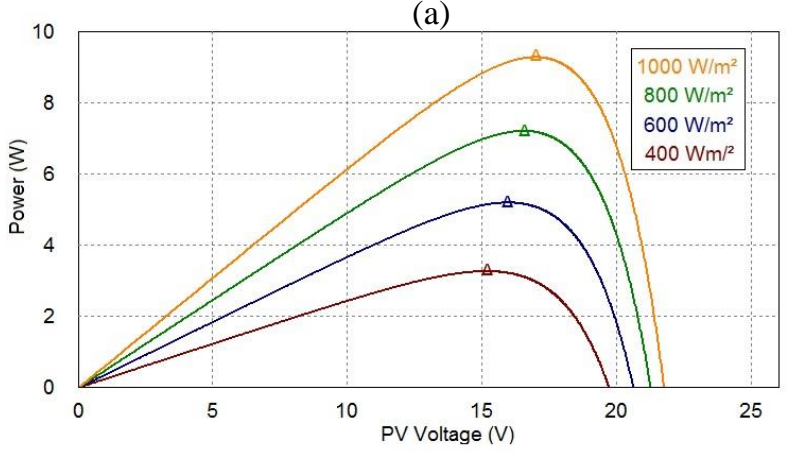

(b)

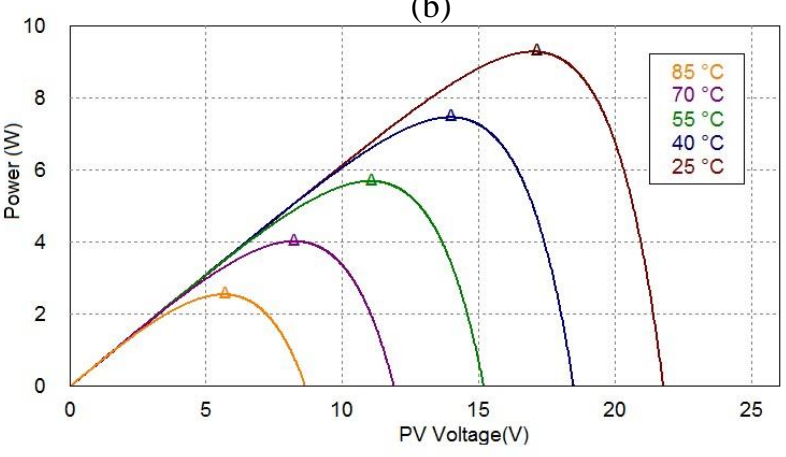

Fig. 4. P-V Characteristic with points of maximum power: (a) at a constant temperature; (b) under constant radiation.

Recovering the foregoing, it is concluded that this method is effective only when the temperature variation in the cell module is very small; otherwise, the operating point deviates from the point MPP, in proportion to the temperature increase. To try to overcome this problem, Tracking Method Based on Temperature Measurement was implemented in the circuit [5], using an approximate linear equation to a set voltage according to the temperature of the photovoltaic panel according to equations (1) and (2).

$$
\begin{gathered}
V_{m p}(T)=V_{m p}^{S T C}+\mu_{V m p}\left(T-T^{S T C}\right) \\
\mu_{V m p}=\frac{V_{m p}^{S T C}-V_{m p 1}}{T_{S T C}-T_{1}}=\frac{V_{m p 1}-V_{m p 2}}{T_{1}-T_{2}}
\end{gathered}
$$

Where $V_{m p}(T)$ is the Voltage that varies with temperature, $V_{m p}^{S T C}$ is the voltage of maximum power at STC conditions, $\mu_{V m p}$ is the slope of the line and $T$ the panel temperature.

Despite implementing this algorithm, the method has the drawback the need for prior knowledge of the maximum output voltage of the PV module at each temperature, so it can be set as a reference. A positive aspect of this method is that only one voltage sensor output and the panel temperature is needed and with a simple control circuit can reach the MPP. The block diagram of the MPPT algorithm is shown in Fig. 5

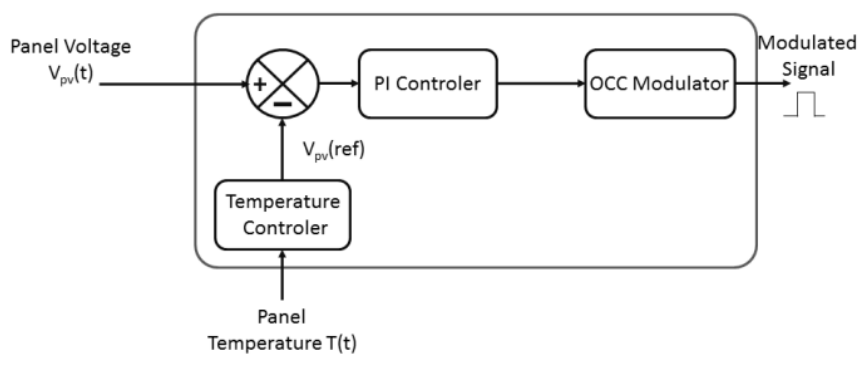

Fig. 5. Block Diagram of tracking algorithm.

\section{One Cycle Control - OCC}

The OCC is a nonlinear control method that achieves the dynamic control of the average value of a switched variable instantly. In other words, you only need a switching cycle so that the average value of the switching variable reaches a new equilibrium state after a transient. The main feature of the OCC technique is established by controlling the amplitude of a carrier and not the control variable, as is usually done by other techniques such as PWM. The basic scheme of a OCC controller is shown in Fig. 6. It consists of a resettable integrator, a comparator, a flip-flop RS and an oscillator to generate the clock signal.

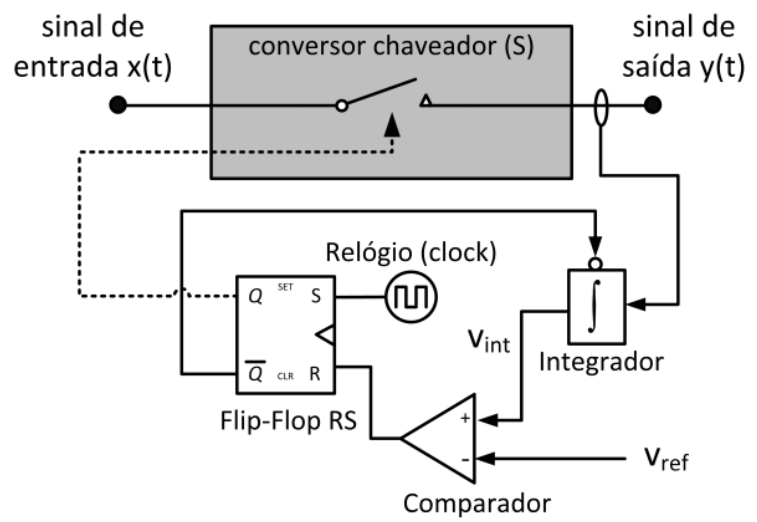

Fig. 6. Block diagram of One Cycle Control.

For a constant frequency switching, $\mathrm{T}_{\mathrm{S}}$ is constant. The purpose of OCC is to adjust the switching $\mathrm{T}_{\mathrm{ON}}$ in each cycle so that the integral value of the waveform is constant. The oscillator determines the switching period $\mathrm{T}_{\mathrm{S}}$ (constant) using the clock signal. For a time $\mathrm{t}_{\mathrm{on}}$ (on) the key is closed and during $t_{\text {off }}$ (off) the switch is open, where $\mathrm{T}_{\mathrm{S}}=\mathrm{t}_{\mathrm{on}}+\mathrm{t}_{\mathrm{off}}$. The switch cuts off the input signal $\mathrm{x}(\mathrm{t})$ and provides the output signal $\mathrm{y}(\mathrm{t})$ can be described in equation (3).

$$
y(t)=\left\{\begin{array}{c}
x(t), 0 \leq t \leq t_{\text {on }} \\
0, t_{\text {on }}<t \leq T_{S}
\end{array}\right.
$$

The mean value of $\mathrm{y}(\mathrm{t})$ over a switching period is calculated using equation (4): 


$$
\bar{y}=\frac{1}{T_{S}} \int y(t) d t=\frac{1}{T_{S}} \int_{0}^{t_{\text {on }}} x(t) d t
$$

In OCC the oscillator frequency must be much higher than the frequency of the input signal $x(t)$ and the reference $V_{\text {ref }}(t)$. When the period of these signals is compared with the oscillator period, they can be regarded as constants, i.e., $x(t)=X$ and $V_{\text {ref }}(t)=V_{\text {ref. }}$. The instant that the logic level of the clock signal is "1", the output $\mathrm{Q}$ assumes logic "1" closing the key, and its inverted output assumes logic " 0 " by resetting the integrator. The duty cycle defined by $\mathrm{D}=\mathrm{t}_{\mathrm{on}} / \mathrm{T}_{\mathrm{S}}$ is modulated so that the integration of the output signal $y(t)$ is equal to the reference voltage $V_{\text {ref }}(t)$.

The Fig. 7 shows the waveforms of OCC for a simulation in PSIM software on the signal $\mathrm{x}(\mathrm{t})$ varies from $1.5 \mathrm{~V}$ to $3.5 \mathrm{~V}$ in $500 \mu \mathrm{S}, \mathrm{V}_{\text {ref }}$ is $10 \mathrm{~V}$, and the clock frequency is $10 \mathrm{KHz}$. In each cycle the carrier $\mathrm{V}_{\text {int }}(\mathrm{t})$ reaches the same value $V_{\text {ref }}$ of reference and the modulated control signal changes its value from logic "1" to logic "0" until the next cycle begins.

(a)

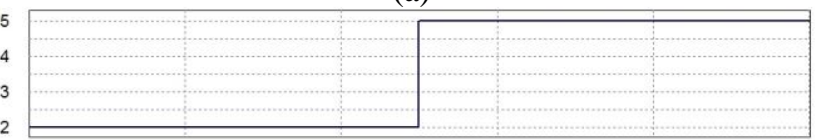

(b)

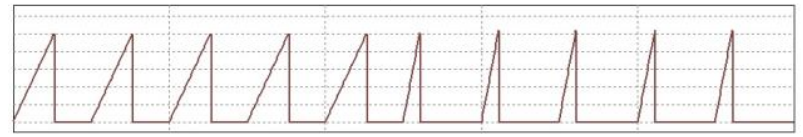

(c)

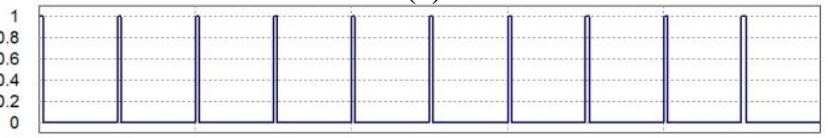

(d)

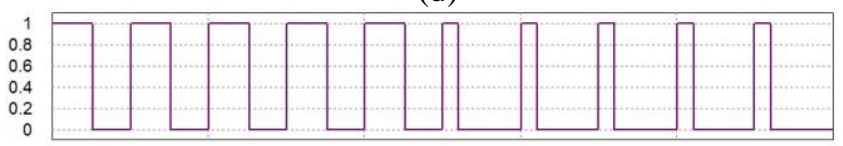

(e)

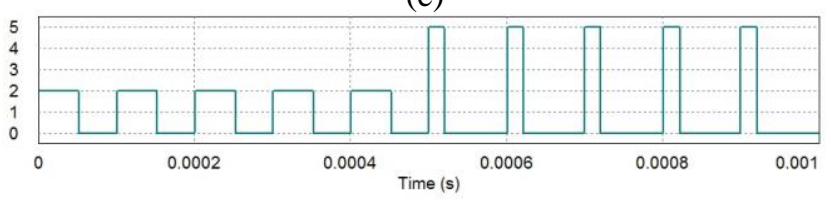

Fig. 7. Waveforms of OCC modulator. (a) Signal $x(t)$ input. (b) The integrator signal. (c) Clock. (d) Modulated control signal. (e) Signal y(t) output.

\section{Simulation Results}

The simulations were performed using PSIM software version 9.1.1.400 in order to prove the performance of the proposed control system. The voltage and power were analysed on the panel for diverse situations as a load change, variations in solar radiation of the step type and linear type ramp and comparing the effects of voltage reading when there is a change in temperature and the method of constant voltage - CV .

The tracking algorithm and the OCC modulator were embedded in digital form, making it the most flexible and accurate system in question parameterization of the system operating point. In the analog form, has the advantage of not using an analog/digital converter, thus, it avoids conversion error. But the disadvantage, the analog system can suffer from issue of saturation of operational amplifiers and nonlinearities of the components. The parameters used in the circuit was simulated are shown in Table 1.

Table I. - Circuit Parameters

\begin{tabular}{|l|c|}
\hline \multicolumn{1}{|c|}{ Element } & Value \\
\hline $\mathrm{R}_{\mathrm{o}}$ & $80 \Omega$ \\
\hline $\mathrm{C}_{\mathrm{o}}$ & $220 \mu \mathrm{F}$ \\
\hline $\mathrm{C}_{\mathrm{pv}}$ & $680 \mu \mathrm{F}$ \\
\hline $\mathrm{L}_{\mathrm{i}}$ & $1,7 \mathrm{mH}$ \\
\hline Clock & $10 \mathrm{kHz}$ \\
\hline Clock duty cycle & 0,05 \\
\hline
\end{tabular}

The temperature control will deliver the PI to the controller reference voltage $\mathrm{V}_{\mathrm{REF}}$ of the maximum power point, according to equation (1). Upon receiving the specification $\mathrm{V}_{\mathrm{REF}}$, the controller compares the read panel output voltage $\mathrm{V}_{\mathrm{PV}}$ and the reference voltage, generating an error value. This error will go through a PI controller with $K_{I}$ integration constant and a gain $K_{P}$. For a quick response to the slightest mistake the $\mathrm{K}_{\mathrm{P}}$ and $\mathrm{K}_{\mathrm{I}}$ values are respectively 10 and 0,00001 . After this step, the output of

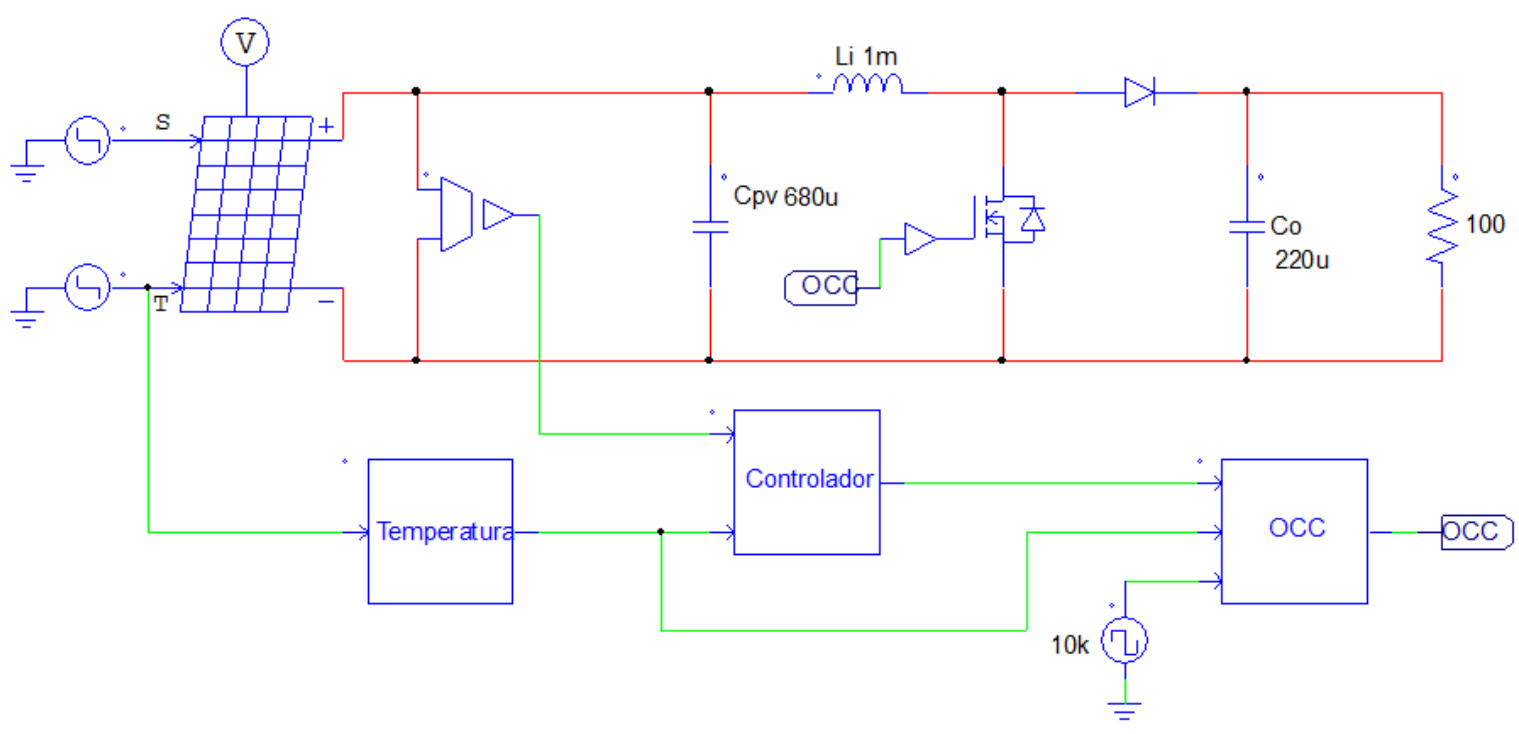


the MPPT is a reference value that the OCC modulator will converge to a duty cycle value $\mathrm{D}$ and apply the power stage boost converter. The Boost converter will make the PV panel delivered maximum power at that moment.

Next, we will conduct some tests to see if the system will converge to the point of MPP, it is robust to disturbance rejection and variations in radiation and temperature.

\section{A. First test-Load Variation.}

First, we will perform a variation in the drive load, considering the STC conditions, $100 \Omega$ resistor to $50 \Omega$. This simulation was done by adding another $100 \Omega$ resistor in parallel at time $\mathrm{T}=0,2 \mathrm{~s}$. We can observe in Fig. 9(a) that the power remain almost constant after the load variation in OCC scheme, the power becomes a little oscillatory but follows the reference MPP. In Fig. 9(b) we can observe the integrator signal of OCC modulator operating in load variation. In Fig. 9(c) the PWM scheme we can observe that stabilization time is longer than OCC but the reference is achieved like OCC.

(a)

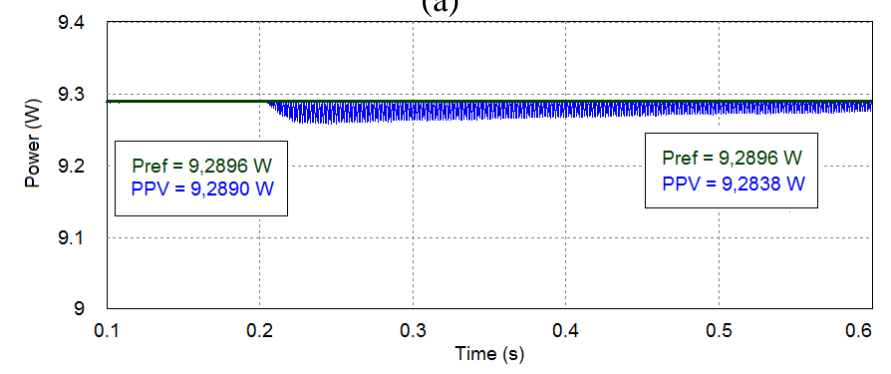

(b)

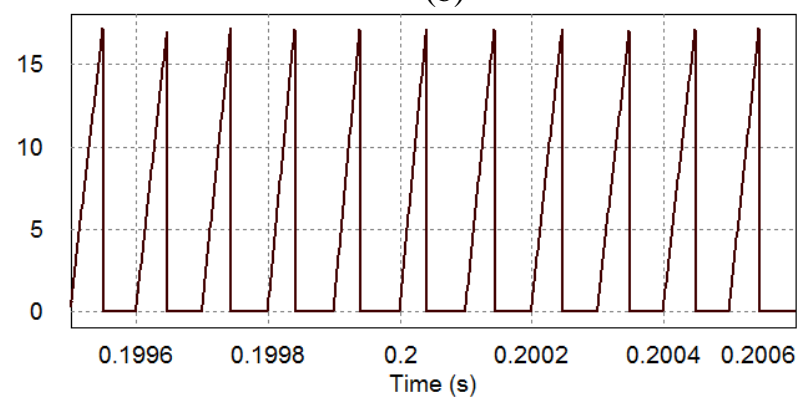

(c)

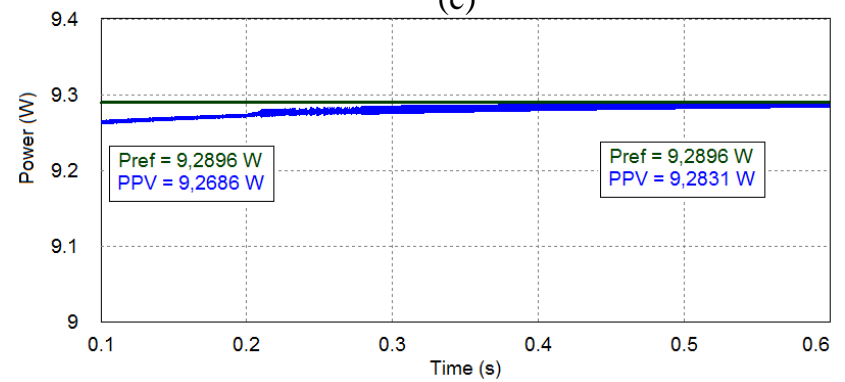

Fig. 9. System waveforms: (a) PV Power with digital OCC modulator. (b) Integrator Signal of OCC modulation (c) PV Power with PWM modulator.

\section{B. Second test - Step Variation of Radiation: $1000 \mathrm{~W} / \mathrm{m}^{2}$ to $700 \mathrm{~W} / \mathrm{m}^{2}$ with constant temperature.}

Now, a step variation in solar irradiance of $1000 \mathrm{~W} / \mathrm{m}^{2}$ to $700 \mathrm{~W} / \mathrm{m}^{2}$ at the instant 0,2 seconds was performed, and maintaining the temperature at $25^{\circ} \mathrm{C}$, as shown in Fig. 10 .
We can see that when it happens the change of radiation from $1000 \mathrm{~W} / \mathrm{m}^{2}$ to $700 \mathrm{~W} / \mathrm{m}^{2}$, the OCC algorithm responds faster than the PWM due to the fact of having the highest speed of convergence. Both algorithms fail to zero the error between the reference and measured as change in radiation causes a slight shift in the value of maximum power voltage $\mathrm{V}_{\mathrm{MPP}}$, as shown in Fig. 4(a). The Fig. 10 show the PV power reference and the power achieved in $1000 \mathrm{~W} / \mathrm{m}^{2}$ and $700 \mathrm{~W} / \mathrm{m}^{2}$. This corresponds to an error of $0,0065 \%$ at $1000 \mathrm{~W} / \mathrm{m}^{2}$ and $0,83 \%$ at $700 \mathrm{~W} / \mathrm{m}^{2}$ in OCC and $0,22 \%$ at $1000 \mathrm{~W} / \mathrm{m}^{2}$ and $1,84 \%$ at $700 \mathrm{~W} / \mathrm{m}^{2}$ in PWM.
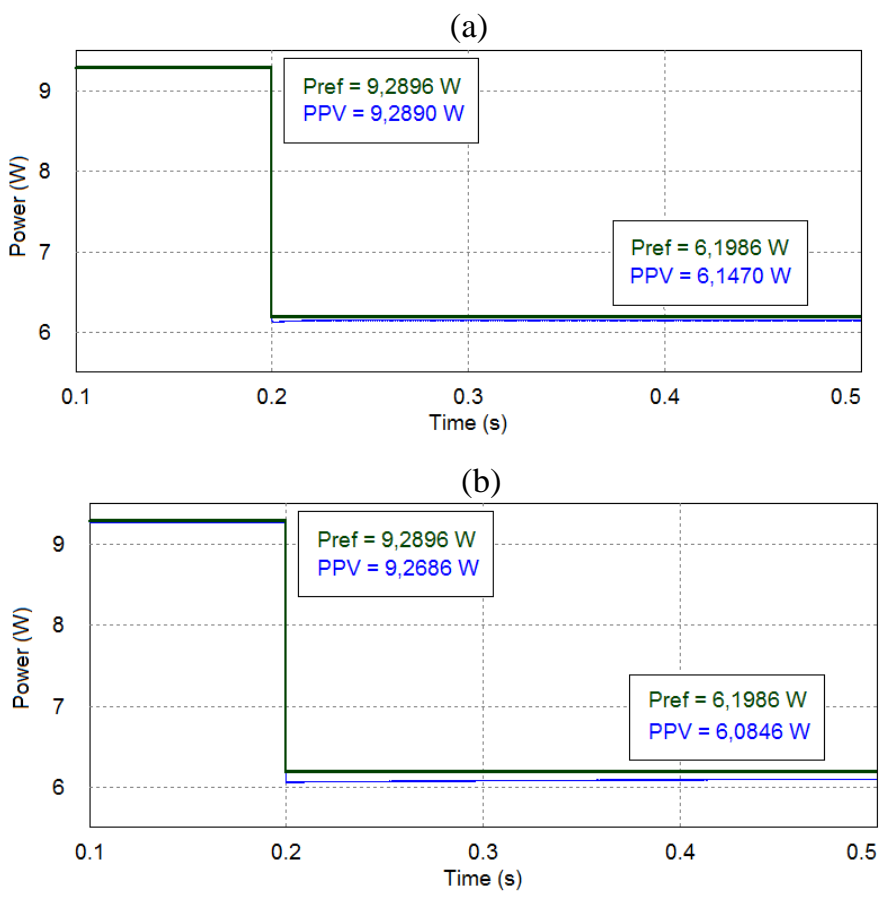

Fig. 10. System waveforms (a) Signal with digital OCC modulator. (b) Signal with PWM analog modulation when the radiation decreases from $1000 \mathrm{~W} / \mathrm{m}^{2}$ to $700 \mathrm{~W} / \mathrm{m}^{2}$ in step type variation.

\section{Third test - Linear Variation of Radiation: $1000 \mathrm{~W} / \mathrm{m}^{2}$ to $700 \mathrm{~W} / \mathrm{m}^{2}$ with constant temperature}

In this test we vary linearly radiation from $1000 \mathrm{~W} / \mathrm{m}^{2}$ to $700 \mathrm{~W} / \mathrm{m}^{2}$ maintaining the temperature at $25^{\circ} \mathrm{C}$ and we observe that in OCC modulation the power returns to reference faster and less error than a PWM modulation. The Fig. 11 show the PV power reference and the power achieved in $1000 \mathrm{~W} / \mathrm{m}^{2}$ and $700 \mathrm{~W} / \mathrm{m}^{2}$. This corresponds to an error of $0,04 \%$ at $1000 \mathrm{~W} / \mathrm{m}^{2}$ and $1,18 \%$ at $700 \mathrm{~W} / \mathrm{m}^{2}$ in OCC and $0,4 \%$ at $1000 \mathrm{~W} / \mathrm{m}^{2}$ and $2,3 \%$ at $700 \mathrm{~W} / \mathrm{m}^{2}$ in PWM. 


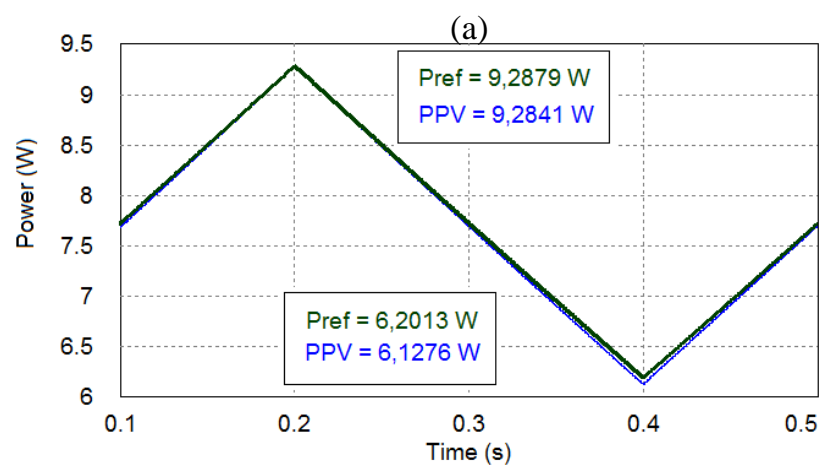

(b)

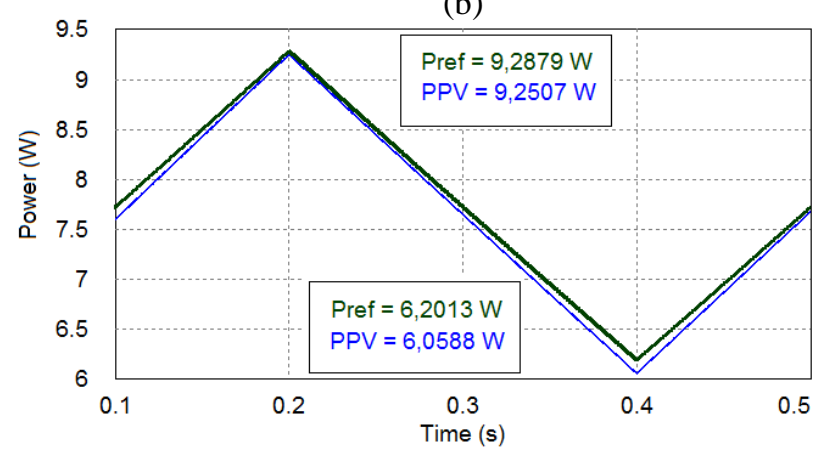

Fig. 11. System waveforms (a) Signal with digital OCC modulator. (b) Signal with PWM analog modulation in the linear change radiation from $1000 \mathrm{~W} / \mathrm{m}^{2}$ to $700 \mathrm{~W} / \mathrm{m}^{2}$.

D. Fourth test - Linear Variation of Temperature: $25^{\circ} \mathrm{C}$ to $35^{\circ} \mathrm{C}$ with constant Radiation

In this test we implemented a degree of variation in temperature from $25^{\circ} \mathrm{C}$ to $35^{\circ} \mathrm{C}$ maintaining the radiation at $1000 \mathrm{~W} / \mathrm{m}^{2}$, as shown in Fig. 12. We can observe in 12(a) that the Tracking Method Based on Temperature Measurement works well for a variation of $10^{\circ} \mathrm{C}$.

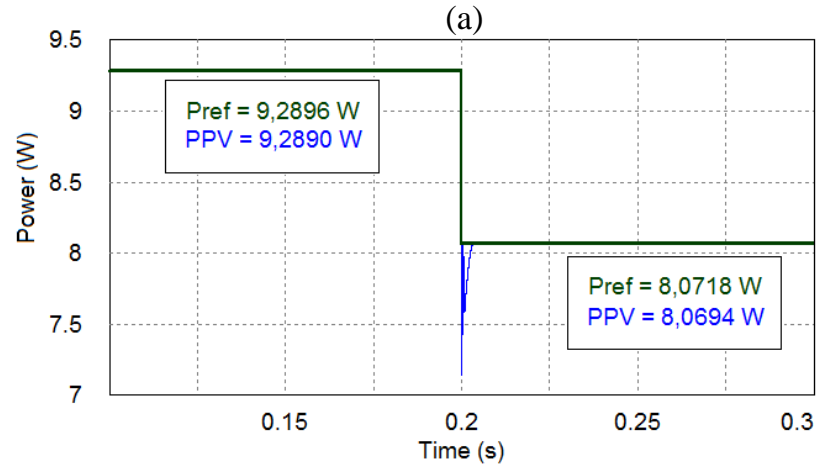

(b)

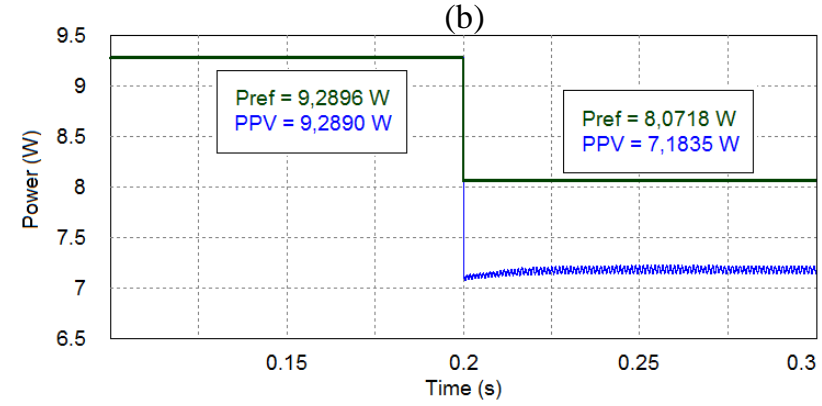

Fig. 12. (a) Power with digital OCC modulator and Tracking Method Based on Temperature Measurement. (b) Power of only digital OCC modulator with Constant Voltage when the temperature increases from $25^{\circ} \mathrm{C}$ to $35^{\circ} \mathrm{C}$ in step type variation.
The method of constant voltage without temperature control can't track the maximum power point due to Power versus Temperature curve present a large deviation of the MPP point, seen in Fig 4(b). This corresponds to an error of $0,0065 \%$ at $25{ }^{\circ} \mathrm{C} 1000 \mathrm{~W} / \mathrm{m}^{2}$ and $0,03 \%$ at $35^{\circ} \mathrm{C}$ $1000 \mathrm{~W} / \mathrm{m}^{2}$ with temperature control and $0,0065 \%$ at 25 ${ }^{\circ} \mathrm{C} 1000 \mathrm{~W} / \mathrm{m}^{2}$ and $11,01 \%$ at $35^{\circ} \mathrm{C} 1000 \mathrm{~W} / \mathrm{m}^{2}$ without temperature control.

\section{Conclusions}

This paper proposes another switching method for a boost converter using the OCC. It was shown the need to extract the maximum power of the photovoltaic panels and the principle of operation of the OCC.

In the first simulation we can be seen that both OCC and PWM methods have proven efficient in the load change because the panel characteristics have not changed. Also, we have to be careful so that the load does not exceed the maximum power of the panel. In the second and third test we can see that the model control with OCC was quicker and less system error that the PWM. The last test was seen that the temperature measurement for control with the control of constant voltage was quite efficient for temperature changes.

\section{References}

[1] Smedley, K. M. and Cuk, S. One-Cycle Control of Switching Converters. Proceedings of 22nd Annual IEEE Power Electronics Specialists Conference, 1991, pp. 888-896.

[2] Smedley, K. M. and Cuk, S. One-Cycle Control of Switching Converters. IEEE Transactions on Power Electronics, 10 (6), pp. 625- 633, 1995.

[3] Neto, J.T.C., Salazar, A. O. and Lock A. S., One Cycle Control Based Maximum Power Point Tracker Applied in Photovoltaic Systems, IEEE Latin America Transactions, Vol. 14, No. 2, Feb 2016.

[4] Brito, M. A. G., Sampaio, L. G. Jr, L. P., Melo, G. A., Canesin C. A., Evaluation of the Main MPPT Techniques for Photovoltaic Applications, IEEE Trans. on Industrial Electronics, vol.60, no. 3, pp. 1156-1167, March. 2013.

[5] Coelho, R.F; Concer, F.M; Martins, D.C; A MPPT approach based on temperature measurements applied in PV systems, IEEE International Conference on Sustainable Energy Technologies, 2010. pp. 1-6. 